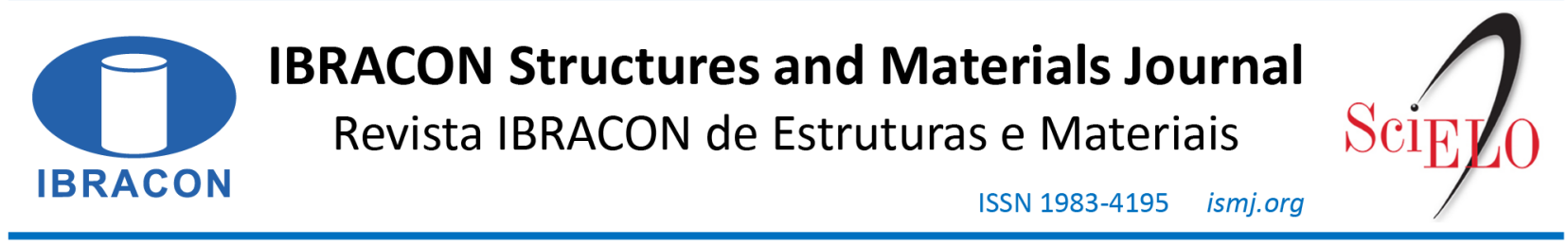

ORIGINAL ARTICLE

\title{
Proposition and analysis of strut and tie models for short corbels from techniques of topology optimization
}

\section{Proposição e análise de modelos de bielas para consolos curtos a partir de técnicas de otimização topológica}

\author{
Matheus Barbosa Moreira Cedrim ${ }^{\mathrm{a}}$ (10 \\ Eduardo Nobre Lages ${ }^{\mathrm{b}}$ \\ Aline da Silva Ramos Barboza ${ }^{\mathrm{b}}$
}

${ }^{\mathrm{a} C e n t r o ~ U n i v e r s i t a ́ r i o ~ C E S M A C ~-~ C E S M A C, ~ M a c e i o ́, ~ A L, ~ B r a s i l ~}$

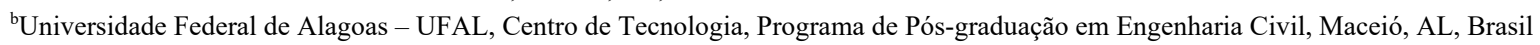

Received 23 January 2020 Accepted 10 July 2020

\begin{abstract}
Reinforced concrete short corbels are components characterized to represent typical conditions of geometrical and static discontinuity. In general, the classical bending theory is not valid for their design. With the strut and tie method, a model of a self-balanced truss, a strategy of representation of the principal stress flow appears as a representation of the trajectories of the main stresses in these components. Within the context of obtaining the strut and tie models, topology optimization is an indicated technique for an automated process. Combined with a numerical analysis based on finite elements, the SIMP (Solid Isotropic Material with Penalization) method formulation, which is defined with the criterion of minimum strain energy restricted by the volumetric fraction, is used for the development of the models with the ABAQUS® v. 6.14.1 software. Therefore, with the material distribution posterior to the optimization and the validation based on normative codes, it is demonstrated that the tool is effective in the development of strut and tie models.
\end{abstract}

Keywords: corbels, topology optimization, SIMP.

Resumo: Os consolos curtos de concreto armado são componentes caracterizados por representarem situações típicas de descontinuidade geométrica e estática. Para o seu dimensionamento, em geral, não é válida a teoria clássica da flexão. Com o método das bielas, um modelo de treliça autoequilibrada surge como uma representação das trajetórias de tensões principais nesses componentes. No contexto de obtenção dos modelos de bielas, a otimização topológica é uma técnica indicada para um processo automatizado. Combinado com uma análise numérica em elementos finitos, a formulação do método SIMP (Solid Isotropic Material with Penalization), que é definida com o critério da mínima energia de deformação com restrição de volume, é utilizada para a definição dos modelos com o software ABAQUS® v. 6.14.1. Assim, com a distribuição de material após a otimização e a validação feita a partir de recomendações normativas, mostra-se que a ferramenta é eficaz no auxílio no desenvolvimento de modelos de bielas.

Palavras-chave: consolos, otimização topológica, SIMP.

How to cite: M. B. M. Cedrim, E. N. Lages, and A. S. R. Barboza, "Proposition and analysis of strut and tie models for short corbels from techniques of topology optimization," Rev. IBRACON Estrut. Mater., vol. 14, no. 2, e14212, 2021, https://doi.org/10.1590/S1983-

41952021000200012

\section{INTRODUCTION}

In most of the one-dimensional bent elements in structural concrete, the design is based on the Euler-Bernoulli hypothesis, in which the cross-section, which is initially plane, remains plane, and results in a linear distribution of the specific longitudinal strains along the height of the bent element. For cases of special elements that contain discontinuity

Corresponding author: Matheus Barbosa Moreira Cedrim. E-mail: matheuscedrim@hotmail.com

Financial support: National Council for Research and Development (CNPq).

Conflict of interest: Nothing to declare. 
regions, the strain distribution in the cross-section is not linear, which causes the structural problem to become more complex.

Among the elements used in precast structures, short corbels, dapped-beams, and pedestal walls are mentioned in Brazilian code NBR 9062 [1] as elements that are featured as discontinuity regions in the structural system and, for this reason, analyzed using the strut and tie model. With this methodology, it is possible to evaluate the structural behavior by an idealized truss, as shown in Figure 1 [2].

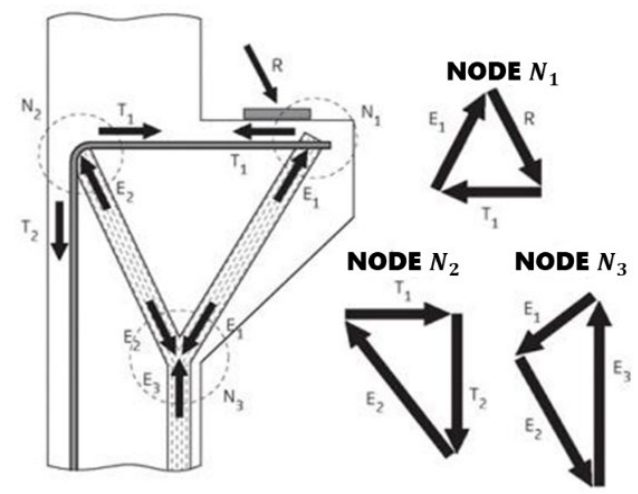

Figure 1. Static scheme of a strut and tie model for a short corbel.

To obtain the strut and tie model, it is common to make use of numerical methods to understand the structural behavior of special elements. Currently, the codes which consider the concrete structure design, for example, NBR 6118 [3], already suggest the use of the Finite Element Method (FEM) for the visualization of the load path by principal stress trajectories.

To help in the correct positioning of the struts in the inner side of the structure, Liang et al. [4] proposed using structural optimization techniques, which allow the positioning of the bar elements over the principal stress flow found in the linear elastic analysis.

Pantoja [5] also used these techniques to automatize the topological models, besides considering the aspects related to obtaining the failure probability by a reliability analysis.

Through evolutionary methods, Liang [6], Almeida et al. [7], Guerra [8], Guerra and Greco [9] used tools based on criteria for removing elements, represented by the quantities of stiffness contribution. Thus, based on the observation that if the element is no longer necessary to the structure, its contribution to the stiffness will progressively decrease, and this will reflect on attenuation in a constitutive matrix, as if it were in a damage process.

Once there is not only one specific approach in the solution for obtaining the strut and tie model, the development of new applications is a relevant factor. Besides this, there are different paths for its definition, the design codes for reinforced concrete structures NBR 6118 [3], ACI 318 [10], and Eurocode 2 [11] do not use the approach of topology optimization as a scheme for obtaining these models.

To help in choosing the truss model that better represents the structural behavior, the topology optimization technique, which consists of the optimized material distribution inside a previously established project domain, is presented as a promising alternative for this function.

It should be noted that the optimized topologies are balanced systems; however, no strength control is checked in the nodes and the other elements with the optimization algorithm. This procedure only produces preliminary patterns, and the entire design and checking of strut, ties, and nodal regions are the job of the engineer.

These analyses, based on appropriate volumetric fractions for the interpretation of structural behavior, assist the development of strut and tie models in a discerning manner, since the mathematical foundation is used to maximize the stiffness.

\section{THEORETICAL REFERENCE}

Corbels are structural elements that need different strategies of design, due to the evidenced discontinuity in the stress flow of the structural system. 


\subsection{Design models of short corbels}

El Debs [2] conceptualizes that concrete corbels are characterized as structural elements that protrude from columns or walls to serve as a support for the other parts of the structure or for utilization loads.

The classification between short, very short, and long is related to distance "a", measured from the action line of the applied load in the bearing pad to the external face of the column, with the effective depth "d". According to NBR 6118 [3], the corbel is short if $d / 2 \leq \mathrm{a} \leq \mathrm{d}$ and very short if $\mathrm{a}<\mathrm{d} / 2$. In the case where $\mathrm{a}>\mathrm{d}$, the element should be analyzed as a cantilever beam.

Figure 2 [12] illustrates the discontinuity regions found in different corbels. In order to obtain a safe design for these elements, the boundary conditions of each problem should be considered individually. This way, each case will lead to a different conception of the strut and tie model.
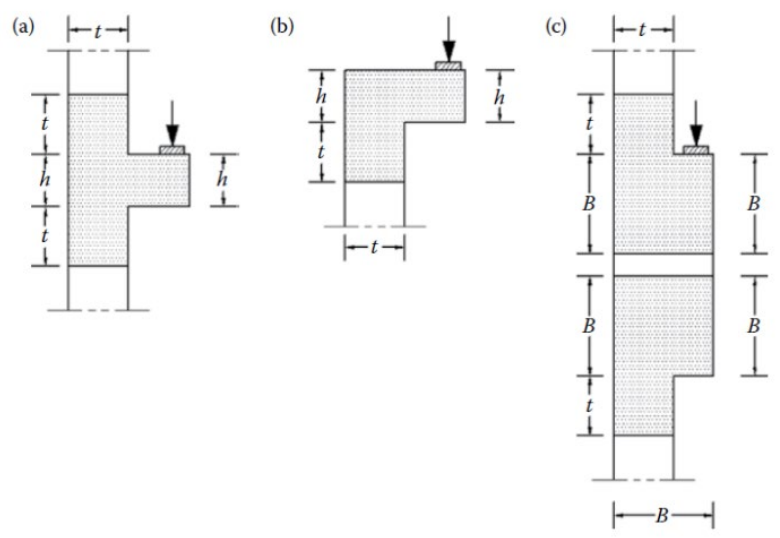

Figure 2. Discontinuity regions in corbels.

Through an analysis of strut and tie models, the behavior of a short corbel is idealized as a straight tie in the superior face, which, for constructive issues and ease of execution, does not necessarily follow the medium path of the tension stresses, once they are slightly inclined. To ensure the ductility of the elements, a secondary reinforcement is also placed, made up of horizontal stirrups.

The utilization of an integrated process for obtaining the strut and tie models through topology optimization is still an open issue. Liang [6] quotes that most of the topology optimization algorithms are still not developed for practical applications, and, are emphasized, mainly, on mathematical aspects. However, with the advance of computational development, a greater agility for the definition of structural projects is aimed.

Williams et al. [13] comment that the flexibility of the strut and tie models often causes uncertainties in engineers: there is no "correct" model for any particular structure. If the required principles to achieve a static solution based on the lower bound limit of the theory of plasticity are accomplished, the engineer is able to assure that the adopted model is safe.

\subsection{Strut and tie models}

Schlaich et al. [14] proposed that the strut and tie model may be adopted considering the stress flow in the structure, using the load path process. Once the stresses and their principal directions originated from the linear elastic analysis, the development of the model should represent these stresses in a region as well as possible.

Souza [15] relates that the representation of strut and tie generally is a function of the structure geometry and the acting forces in the contour. The model geometry can be usually obtained by analyzing the following aspects: types of load, angles between struts and ties, area of application of actions and reactions, number of reinforcement layers, and covering of reinforcements.

El-Metwally and Chen [12] conceptualize that the strut and tie model is a logical extension of the truss model proposed by Ritter and Mörsch. The greatest difference between these two methods is that the strut and tie model is a set of balanced loads, but it does not necessarily form a stable truss system. Therefore, it is a model that can be considered as a generalization of the truss analogy. 


\subsection{Considerations for obtaining the strut and tie models}

In order to conceive a design model for corbels through a mathematical formulation, the topology optimization with the use of the Finite Element Method (FEM) is conceptually indicated for the conception of structural element projects. In this study, a formulation of topology optimization for linear elastic materials was adopted.

For Liang et al. [4], the consideration of elastic behavior for concrete, even in cracking situations, provides a clear understanding of the load transfer in reinforced concrete elements. As an indication to perform a strut and tie model, the obtained results through topological optimization of linear elastic structures should not be considered absolute; however, there are confirmations that these results are valid and checked by experimental analyses.

According to NBR 6118 [3], for the strut and tie model conception, it is possible to validate the application of the obtained results through analyses that consider linear elastic materials. This way, exceptionally, for the visualization of principal stress trajectories, the referred code allows the application of the finite element models with this simplification of analysis.

It is emphasized that for the technical reference NBR 6118 [3], the reinforcement design should not be limited only to the internal loads or stresses obtained through this analysis, but also that the necessary minimum and maximum quantities should be respected, demanded by the structural concrete theory, to assure the ductility of the elements.

Schlaich et al. [14] propose that the model geometry is based on elastic stress fields and the design follows the theory of plasticity. With this, from a practical point of view, it is possible to treat the ultimate limit state and serviceability limit state in the cracked situation as a unique model for both.

It is worth emphasizing that the serviceability limit state verification is a polemical theme since its consideration is implicit in the strut and tie model. This way, the displacement evaluation of the service loads requires that the adopted model estimate the stiffness of the elements in such a manner as to give an equivalent response to the real displacement of the structure.

\subsection{Numerical modeling}

The structural optimization process consists in obtaining a better performance project, which is evaluated through a defined objective function by a set of variables that describe the system, known as design variables. With the formulation of the method, the design variables defined in the problem are the relative densities related to the finite elements or the nodes of the mesh, such as the example in Figure 3 [16].
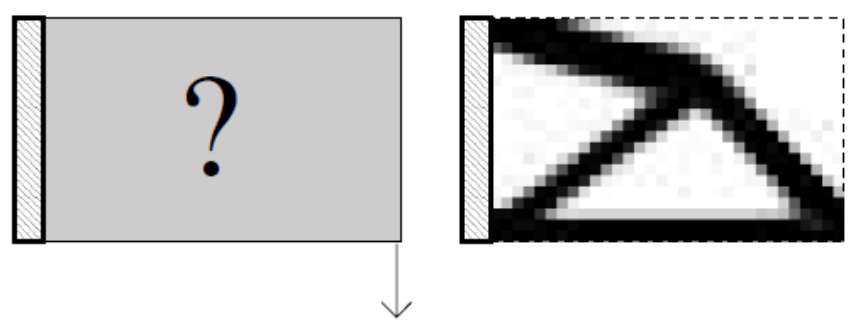

Figure 3. Structural optimization problem

The numerical method based on finite elements most known is the SIMP method, which was developed in the 1980s. The term SIMP means Solid Isotropic Material with Penalization [17].

The objective of the problem of the minimization of compliance or maximization of stiffness can be understood as an iterative process that seeks a better distribution of the design variables in the defined mesh.

A pioneer work on the application of the method is the publication of Sigmund [16], which presents a computational implementation of a 99-line code in MATLAB ${ }^{\circledR}$, which shows its efficiency for educational applications of topology optimization problems. The method formulation is given by:

$\min c(\mathbf{x})=\mathbf{U}^{\mathbf{T}} \mathbf{K U}=\sum_{e=1}^{N}\left(x_{e}\right)^{p} \mathbf{u}_{\mathbf{e}}^{\mathbf{T}} \mathbf{k}_{\mathbf{e}} \mathbf{u}_{\mathbf{e}}$ 
s.t. $V(\mathbf{x})=f V_{0}$

$0<x_{\min } \leq x_{e} \leq 1$

where $\mathbf{U}$ and $\mathbf{F}$ are the global displacement and force vectors, respectively, $\mathbf{K}$ is the global stiffness matrix, $\mathbf{u}_{\mathbf{e}}$ and $\mathbf{k}_{\mathbf{e}}$ are the element displacement vector and stiffness matrix, respectively, $\mathbf{x}$ is the vector of design variables (relative densities of elements), $\mathrm{x}_{\min }$ is a vector of minimum relative densities, $\mathrm{N}$ is the number of elements used to discretize the design domain, $\mathrm{p}$ is the penalization power, $\mathrm{V}(\mathbf{x})$ and $\mathrm{V}_{0}$ are the material volume and design domain volume, respectively, and $\mathrm{f}$ is the prescribed volume fraction.

Sigmund [16] mentions that the material properties are modeled as relative material densities raised to some power multiplied by the material properties of solid material. It was criticized for a while, once it was argued that no physical material exists with properties described by the power-law interpolation. However, it was proven that the power-law approach is physically permissible if simple conditions on the power are satisfied (e.g. $\mathrm{p} \geq 3$ for Poisson's ratio equal to $1 / 3)$.

A minimum value to Young's modulus of an element is adopted to avoid the singularity problem of the structure's stiffness matrix during the process of resolution of the balance equations. A value of $\mathrm{x}_{\min }$ approximately 0.001 is enough to avoid this problem [5].

In this paper, the ABAQUS ${ }^{\circ}$ V. 6.14.1 software was used as a tool for obtaining optimized topologies. The optimization platform available in ABAQUS $®$ is TOSCA, which provides powerful and fast solutions for structural optimization based on finite elements. The flowchart presented in Figure 4 demonstrates the configuration process and execution of optimization inside the platform in use [18].

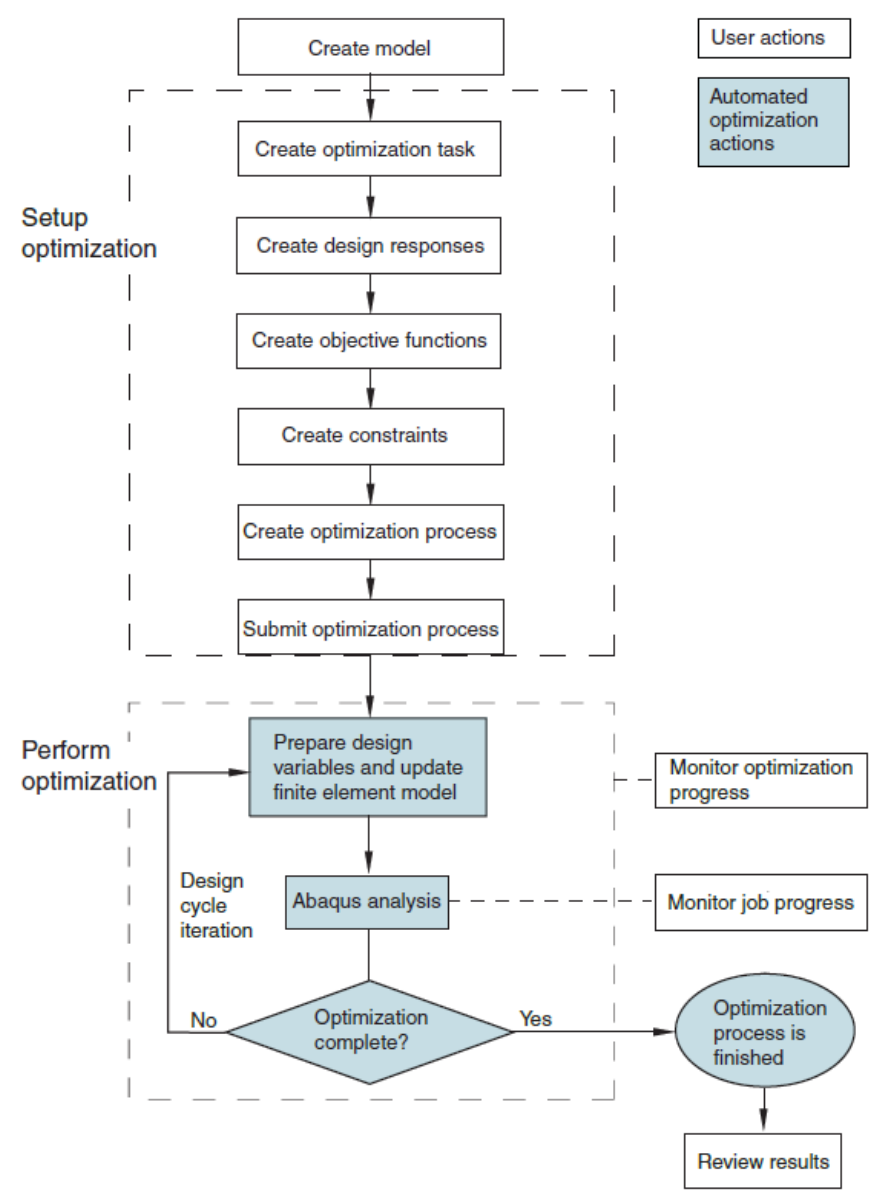

Figure 4. Flowchart of the optimization process. 
The TOSCA Structure provides strategies for new concepts of projects that enable lighter, stiffer, and durable structures. The design development cycle may be directed to maximize or minimize any performance measure, making it possible for the engineer to discover new possibilities.

The nonlinear models, when validated, may contain the association of the elements that represent the reinforcement in a numerical analysis that modifies the behavior of the set. However, a bigger computational cost is demanded due to the cracking consideration during the optimization process, such as the high processing time for the three-dimensional elements, despite $A B A Q U S \AA$ providing a large number of design results for $3 \mathrm{D}$ elements, which can be interesting for the investigation of new optimized models, using, for example, von Mises stresses as constraints.

Once there is not a unique solution for the strut and tie model, different arrangements of bars may represent the same configuration to a given structural disposition. The presented flowchart in Figure 5 shows the adopted procedure. In this work, the optimized material distributions were interpreted as a preliminary pattern of the truss system.

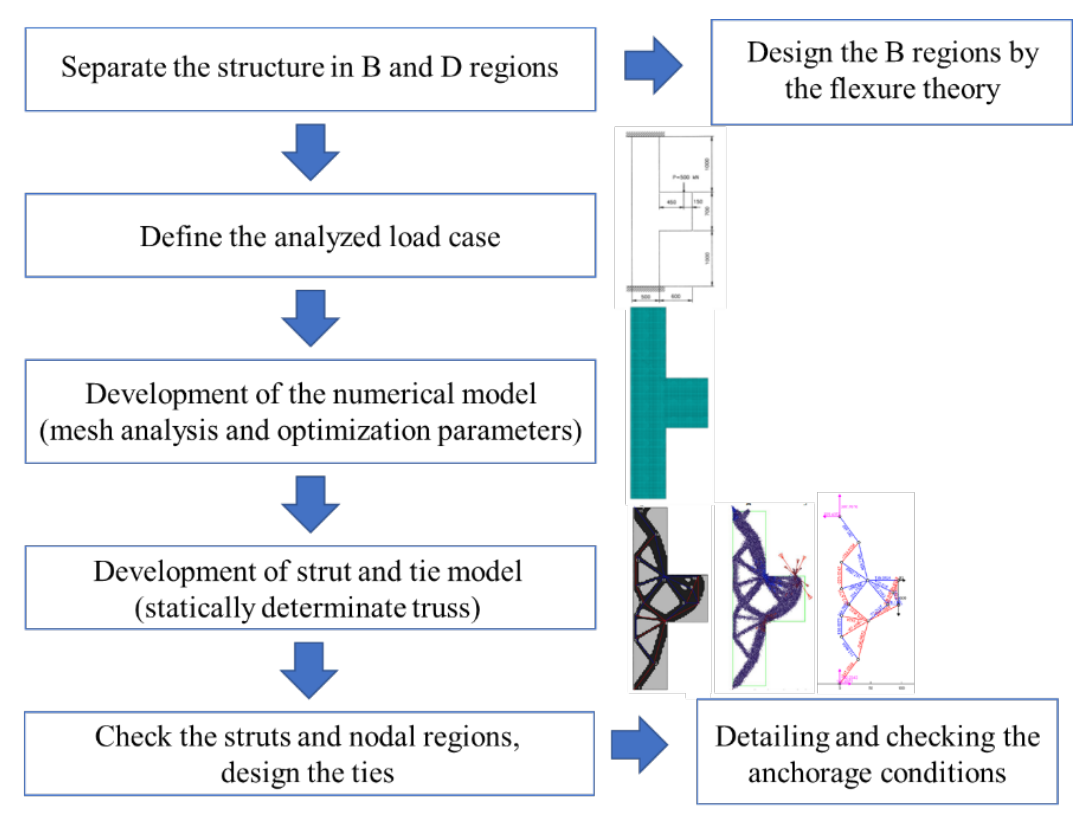

Figure 5. Design sequence with optimization assistance.

For the structural analysis of truss models, commercial software or free codes for computing the internal loads may be used. In this work, a computational code in MATLAB ${ }^{\circledR}$ language was developed, which calculates the axial loads and reaction forces, exclusively from nodal equilibrium equations. For this, to define the node positions, the connectivity of the bars, the prescribed nodal forces, and nodal supports were necessary.

Since there is no consensus of the ideal volume fraction for obtaining the strut and tie model, a critical transition analysis for low values of this fraction must be established. The smaller the volume fraction, harder is the task to interpret the optimized model as an articulated unidimensional model. The bar connection for each volume fraction must follow the closer one that was established for the end of the optimization process.

According to the design codes, the models must be stable, which means statically determinate. To solve this problem, the support conditions and formation law of trusses must be analyzed assuring that the balance is guaranteed.

\section{RESULTS AND DISCUSSIONS}

To obtain the strut and tie models, and use the methodology indicated in the design codes, an example of a rectangular corbel optimization available in the literature and a proposed example of a trapezoidal corbel are presented, with new models for design routines being developed. 


\subsection{Rectangular corbel}

Liang et al. [4] proposed the rectangular corbel illustrated in Figure 6. The a/h ratio is 0.64 . The load, considered punctual, is $500 \mathrm{kN}$. For the boundary condition considerations, the column presents restricted displacements in both ends. The compression strength of the concrete is $\mathrm{f}_{\mathrm{ck}}=32 \mathrm{MPa}$, the longitudinal elastic modulus is $\mathrm{E}=28,567 \mathrm{MPa}$, and the Poisson ratio $v=0.15$, and CA-50 steel (characteristic yield stress $\mathrm{f}_{\mathrm{yk}}=500 \mathrm{MPa}$ ). The column and the corbel widths are presumed as $\mathrm{b}=300 \mathrm{~mm}$.

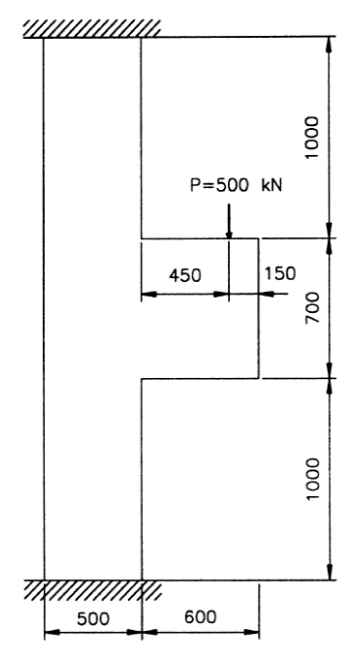

Figure 6. Rectangular corbel (dimensions in $\mathrm{mm}$ )

For modeling, the same element dimensions adopted in the work of Liang et al. were used [4]. A finite element mesh of approximately $25 \mathrm{~mm}$ for plane stress analysis of type CPS4 (quadrilateral element of 4 nodes with bilinear interpolation), 2,832 elements, and 2,985 nodes was considered.

Based on the proposed example, it is noted that the simplification for bidimensional analysis of corbels is indicated for a decrease of computational time, without damaging the interpretation of results. During the process of choosing the mesh, the elements of geometry and computational cost for solving the problem need to be taken into consideration. This way, for more complex problems, a sensitivity analysis of the mesh should be considered, mainly because the analysis via FEM, according to Sigmund [16], offers the possibility of numerical instabilities for the model that may be described in three categories: the checkerboard irregularities, mesh dependence and the problem of optimum location.

Concerning the mesh dependence, the more refined the mesh is in the reference domain, the more similar the structure will be to the predicted layout in the microstructure theory. The solutions' dependence to the chosen discretization leads to better or worse detailing and contour descriptions. To avoid this numerical instability, a sensibility filter adoption is needed. In the simulation using ABAQUS ${ }^{\circledR}$, the filter criterion proposed by Sigmund [16] is adopted. The other instabilities were not evaluated in this work.

For the optimization process, it is considered that the load-applying region is not included since there is no removal of material in this region during the cycles of the project. To define the search direction of minimization, during the processing, the sensibility filter is automatically defined with $\mathrm{r}_{\min }=32.5 \mathrm{~mm}$, and further information is listed in Table 1 .

Table 1. Topology optimization parameters

\begin{tabular}{cc}
\hline Parameters of the SIMP method & Value \\
\hline Minimum density $\left(\rho_{\min }\right)$ & 0.001 \\
\hline Maximum density $\left(\rho_{\max }\right)$ & 1 \\
\hline Maximum change of the density per cycle of project & 0.25 \\
\hline Penalty factor $(\mathrm{p})$ & 3 \\
\hline Convergence criteria & Value \\
\hline Maximum tolerance for the objective function & 0.001 \\
\hline Maximum tolerance for the element density & 0.005 \\
\hline
\end{tabular}


The obtained optimized topologies when considering volume fractions of approximately $90 \%, 80 \%, 70 \%, 60 \%$, $50 \%, 40 \%, 30 \%, 20 \%$, and $10 \%$ of initial volume are presented in Figure 7 . To reach the desired parameters, 15,20 , $34,34,35,36,37,50$ are necessary, respectively, as well as 42 cycles of the project.

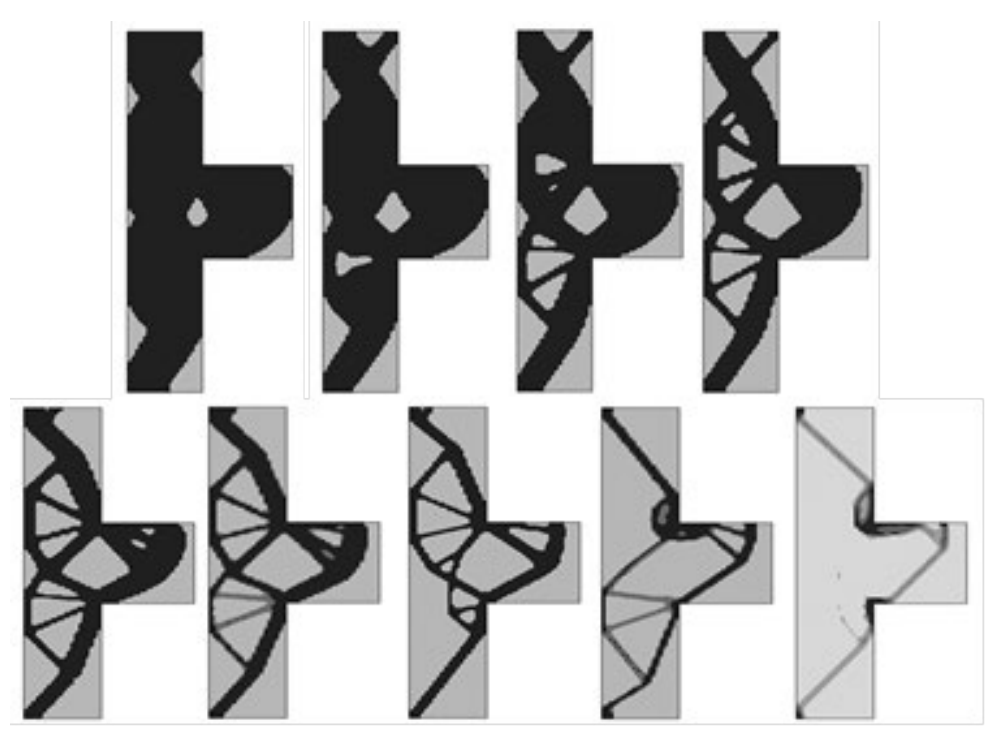

Figure 7. Optimized distribution of material, volume fractions of $90 \%, 80 \%, 70 \%, 60 \%, 50 \%, 40 \%, 30 \%, 20 \%$ and $10 \%$, respectively.

When analyzing Figure 7, the definition of the two regions is carried out. The black region is the one that is considered in the optimization process as the optimized topology, and attends the minimization of the objective function and volume constraint. The grey region is characterized for minimum density $\left(\mathrm{x}_{\min }\right)$, which avoids the singularity in the stiffness matrix.

In Figures 8 and 9 the principal stress trajectories are presented, with the optimized models $f=50 \%$ and $f=40 \%$, respectively. The principal stresses of tension (a) and indicated in blue, and, in red, principal stresses of compression (b). It is verified, therefore, that there is a better visualization of the preliminary truss models.
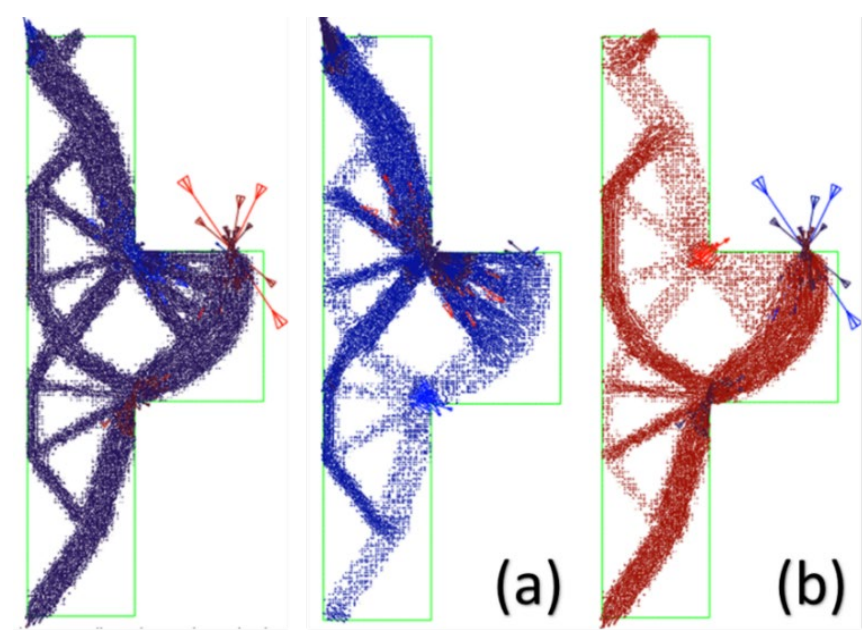

Figure 8. Principal stress trajectories for $\mathrm{f}=50 \%$ (a: tension; $\mathrm{b}$ : compression) 

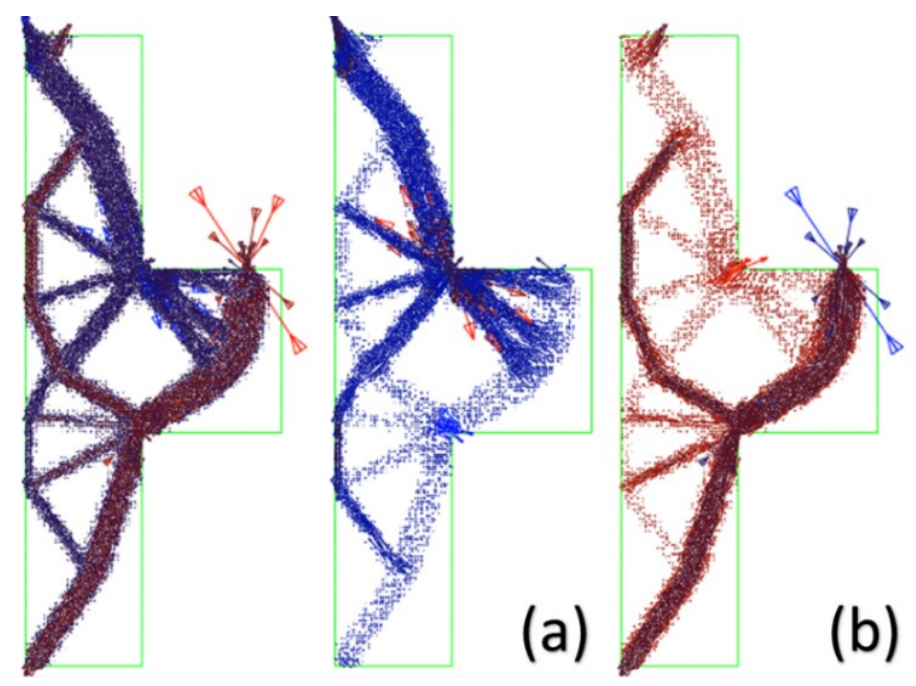

Figure 9. Principal stress trajectories for $\mathrm{f}=40 \%$ (a: tension; $\mathrm{b}$ : compression)

The definition of the truss model, from the bidimensional composition of the material for the bar models, depends on the adopted criteria for each user to accomplish the specific filtering for each case. Therefore, procedures that make the use of the optimum model viable as a reference for building the truss system should be used.

As mentioned before, the topology optimization parameters influence the definition of the final result. The designation of adequate parameters allows a better understanding of the numerical analysis. This way, the emerging of the numerical instabilities is still a concern in the optimization procedure, but these problems can be solved with the adoption of some measures, such as the adequate mesh refinement and correct utilization of the convergence criteria.

In Figure 10, the suggested truss models are shown for the design according to the strut and tie model. The model in Figure 10a is based on the optimized topology found with $\mathrm{f}=50 \%$. The model in Figure $10 \mathrm{~b}$ is based on the optimized topology found with $\mathrm{f}=40 \%$. The node coordinates are presented in Tables 2 and 3 .
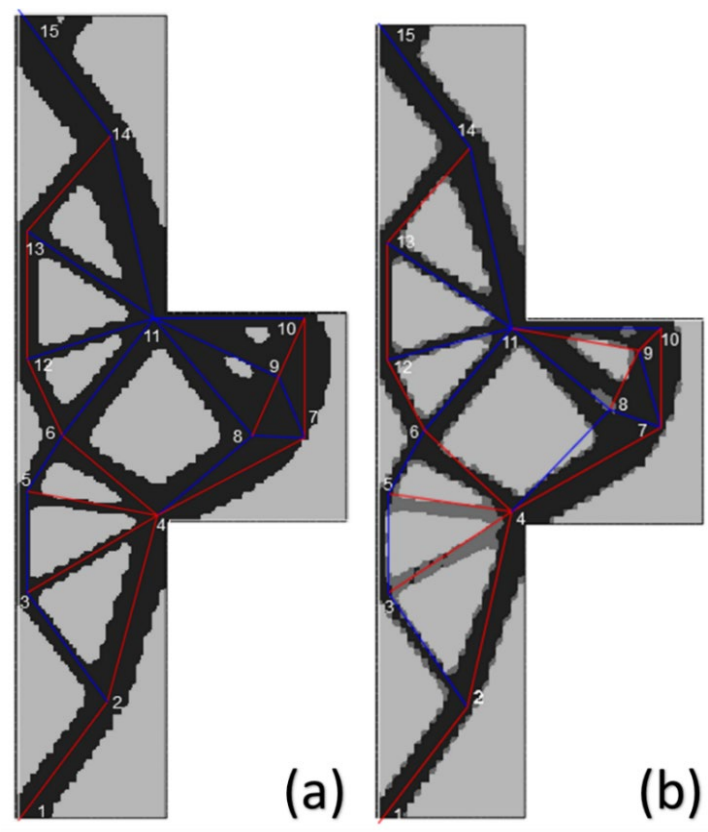

Figure 10. Suggested truss models for the rectangular corbel a) $f=50 \%$; $b$ ) $f=40 \%$ 
Table 2. Coordinates of truss model for $\mathrm{f}=50 \%$

\begin{tabular}{|c|c|c|}
\hline Node & $\mathbf{x}(\mathbf{c m})$ & $y(\mathbf{c m})$ \\
\hline 1 & 0.00 & 0.00 \\
\hline 2 & 29.81 & 39.41 \\
\hline 3 & 3.00 & 75.81 \\
\hline 4 & 46.11 & 101.46 \\
\hline 5 & 3.00 & 109.36 \\
\hline 6 & 14.57 & 128.04 \\
\hline 7 & 95.00 & 127.28 \\
\hline 8 & 77.77 & 128.04 \\
\hline 9 & 86.35 & 147.52 \\
\hline 10 & 95.00 & 167.00 \\
\hline 11 & 45.00 & 167.00 \\
\hline 12 & 3.00 & 153.33 \\
\hline 13 & 3.00 & 196.28 \\
\hline 14 & 30.68 & 228.11 \\
\hline 15 & 0.00 & 270.00 \\
\hline
\end{tabular}

Table 3. Coordinates of truss model for $\mathrm{f}=40 \%$

\begin{tabular}{|c|c|c|}
\hline Node & $\mathbf{x}(\mathrm{cm})$ & $\mathbf{y}(\mathrm{cm})$ \\
\hline 1 & 0.00 & 0.00 \\
\hline 2 & 29.81 & 39.41 \\
\hline 3 & 3.47 & 77.59 \\
\hline 4 & 45.00 & 105.00 \\
\hline 5 & 3.47 & 111.38 \\
\hline 6 & 15.37 & 132.70 \\
\hline 7 & 95.00 & 133.39 \\
\hline 8 & 77.82 & 139.66 \\
\hline 9 & 87.60 & 159.60 \\
\hline 10 & 95.00 & 167.00 \\
\hline 11 & 45.00 & 167.00 \\
\hline 12 & 3.19 & 156.15 \\
\hline 13 & 3.19 & 195.94 \\
\hline 14 & 30.68 & 228.11 \\
\hline 15 & 0.00 & 270.00 \\
\hline
\end{tabular}

For the problem in the analysis, the strut strength according to each normative code are found in Table 4. Conservatively, the strut strength in CCT zones was adopted according to NBR 6118 [3]. For ACI 318 [10], it is considered that there is no transversal reinforcement. In the simplified model of Eurocode 2 [11], the value of the maximum stress in the nodal zone CCC was used as the strength parameter.

Table 4. Strut strength

\begin{tabular}{cc}
\hline Model & Strength $\mathbf{( k N / \mathbf { m } ^ { 2 } )}$ \\
\hline NBR 9062 [1] & $14,350.63$ \\
\hline ACI 318 [10] & $16,320.00$ \\
\hline Eurocode 2 [11] & $15,812.27$ \\
\hline
\end{tabular}

In Figure 11 the internal loads for the two cases are presented. A horizontal load $\mathrm{H}_{\mathrm{d}}=0.16 \mathrm{~V}$ is also applied, following the technical code of NBR 9062 [1]. The positive loads (in blue) indicate tension, while the negative loads (in red) indicate compression. The detail of the loads in the bars for the models $\mathrm{f}=50 \%$ (a) and $\mathrm{f}=40 \%$ (b) in the corbel region are shown, and the steel reinforcement areas are found for the main tie, according to Table 5 . 


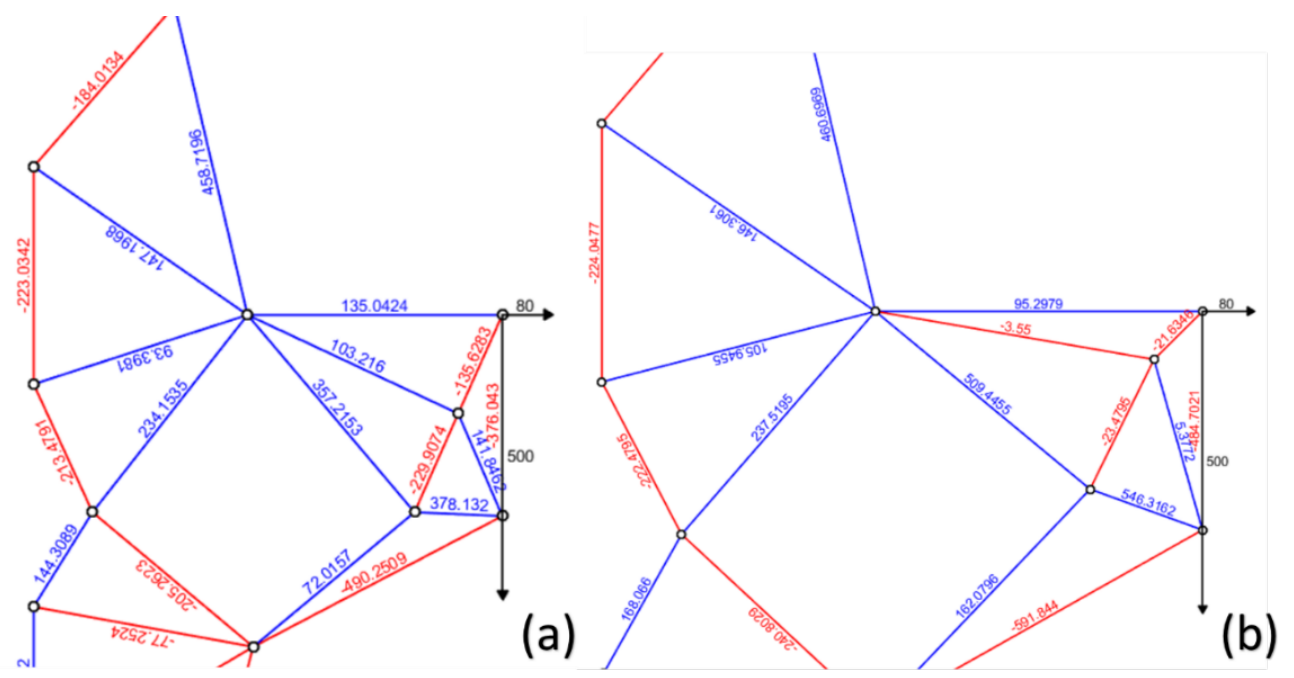

Figure 11. Load details in the rectangular corbel a) $f=50 \%$; $b) f=40 \%$

Table 5. Reinforcement areas of the main tie

\begin{tabular}{cc}
\hline Model & Steel $\left.\mathbf{a r e a ~}_{(\mathbf{c m}} \mathbf{2}\right)$ \\
\hline NBR 9062 [1] & 10.95 \\
\hline PCI (2010) [19] & 15.19 \\
\hline Eurocode 2 [1] & 11.29 \\
\hline
\end{tabular}

Despite containing a horizontal bar in the upper region of the corbel, suggesting that the main tie will be designed for this bar, the maximum load of tension in the two models with optimized topology occurred in an inclined bar, suggesting that the main reinforcement should also be inclined, which is not indicated for the building routine, due to the great probability of occurring a displacement of the reinforcement during the execution.

For the horizontal ties, in the models with $\mathrm{f}=50 \%$ and $\mathrm{f}=40 \%$ (bars $10-11$ ), the steel reinforcement areas were $3.10 \mathrm{~cm}^{2}$ and $2.19 \mathrm{~cm}^{2}$, respectively. When analyzing the inclined ties (bars 11-14 and 7-8), the steel reinforcement areas were $10.55 \mathrm{~cm}^{2}$ and $12.56 \mathrm{~cm}^{2}$, respectively.

Considering the indication of Araújo [20], for the models of two bars, the computation of width of the strut depends on the bearing pad dimensions. Adapted for the case in analysis, for vertical struts, the width $\mathrm{c}_{2}$ was determined for the models with optimized topologies, with the value of $20 \mathrm{~cm}$.

In the model with $\mathrm{f}=50 \%$, the stress in the strut is $6,267.33 \mathrm{kN} / \mathrm{m}^{2}$, and for the model with $\mathrm{f}=40 \%$, the stress in the strut is $8,078.3 \mathrm{kN} / \mathrm{m}^{2}$. Despite the most loaded struts (bars 7-10) being located in the lower region of the corbel, it is highlighted that obtaining these widths was a difficult process.

For the models with optimized topologies, even with the lower strength, in this specific case the one in NBR 6118 [3], presented no concrete crushing, which indicates that the stress levels were safe.

The steel reinforcement areas of the inclined ties obtained through the models with optimized topologies resulted in a good approximation when compared to the design codes. Once each code has its particularity in the definition of the stress and safety factors, the applicability of the developed models through the connectivity of the materials could be verified.

\subsection{Trapezoidal corbel}

The trapezoidal corbel analyzed as an example was proposed by Silva [21], according to Figure 12. After the pre dimensioning suggested by the author, the adopted dimensions for analysis were $\mathrm{a}=58 \mathrm{~cm}, \mathrm{~d}=77 \mathrm{~cm}, \mathrm{~h} 1=40 \mathrm{~cm}$ and $\mathrm{a}_{2}=8 \mathrm{~cm}$. The a/d ratio was 0.75 . The vertical load presented was characteristic. For the horizontal load, $\mathrm{H}_{\mathrm{d}}=0.16 \mathrm{~F}_{\mathrm{d}}$ was considered. 
For the computational analysis, the compression strength of the concrete of $\mathrm{f}_{\mathrm{ck}}=20 \mathrm{MPa}$ was adopted, and the longitudinal elastic modulus was $\mathrm{E}_{\mathrm{cs}}=21,000 \mathrm{MPa}$, Poisson ratio $\mathrm{v}=0.20$ and steel CA-50 (characteristic yield stress $\left.\mathrm{f}_{\mathrm{yk}}=500 \mathrm{MPa}\right)$.

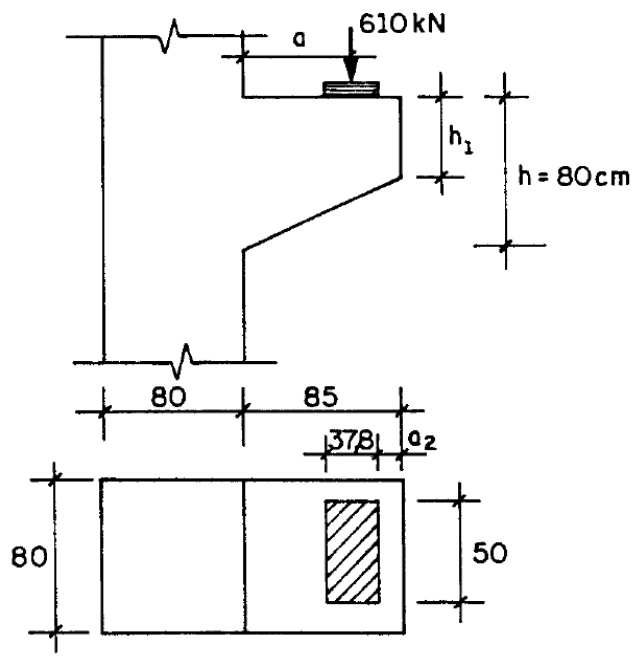

Figure 12. Trapezoidal corbel (dimensions in $\mathrm{cm}$ )

The boundary conditions for this corbel are shown in Figure 13, with the application of the vertical and horizontal loads distributed along the bearing pad and displacement restrictions in the bottom and on the top. The recommendation of El Debs [2] was considered in the modeling. Thus, the resultant loads were applied from a distance of $3 / 4$ of the total length of the corbel $\left(l_{c}\right)$. Therefore, the a/d ratio is 0.83 .
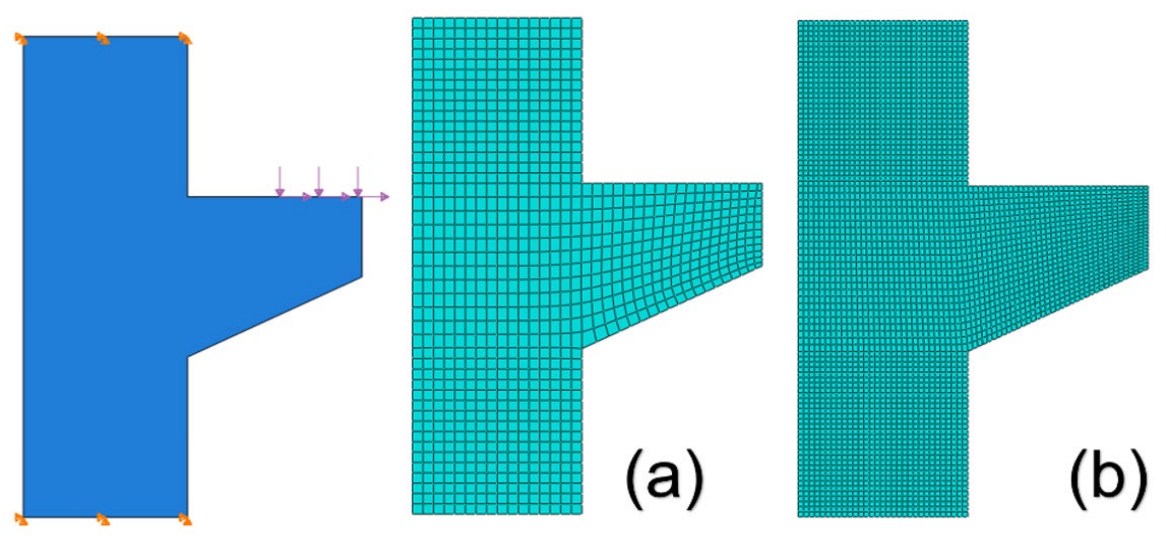

Figure 13. Boundary conditions and analyzed meshes a) dimension of $50 \mathrm{~mm}$; b) dimension of $25 \mathrm{~mm}$

In this example, the modeling with bi-dimensional finite elements was analyzed. A finite element mesh (a) with the approximate size of $50 \mathrm{~mm}$ was considered for plane stress analysis with the element type CPS4 (quadrilateral element of 4 nodes with bilinear interpolation). The model consists of 932 elements, and 1,012 nodes. Considering the same element formulation, the mesh (a) is refined to mesh (b), adopting the approximate mesh size of $25 \mathrm{~mm}$, so the configuration is of 3,680 elements and 3,837 nodes.

Similar to the example of the rectangular corbel, it was considered that the load-applying region was not included in the optimization process since there was no removal of material in this contour. To reduce the mesh dependence, during the processing, the sensibility filter was automatically defined with $r_{\min }=66.3 \mathrm{~mm}$ for mesh (a) and 
$\mathrm{r}_{\min }=33.5 \mathrm{~mm}$ for mesh (b), and further information is listed in Table 1. In this analysis, the optimized topologies were defined for volume fractions below $50 \%$, to reduce the amount of material, approximating the bidimensional model as a possible representation of the truss system.

For mesh (a), the obtained optimized topologies when considering volume fractions of approximately $50 \%, 40 \%$, $30 \%$, and $20 \%$ of the initial volume are presented in Figure 14. To reach the desired parameters, 27, 30, 31, and 34 cycles of project were necessary, respectively. However, for the comparison, the results of mesh (b) were also analyzed.
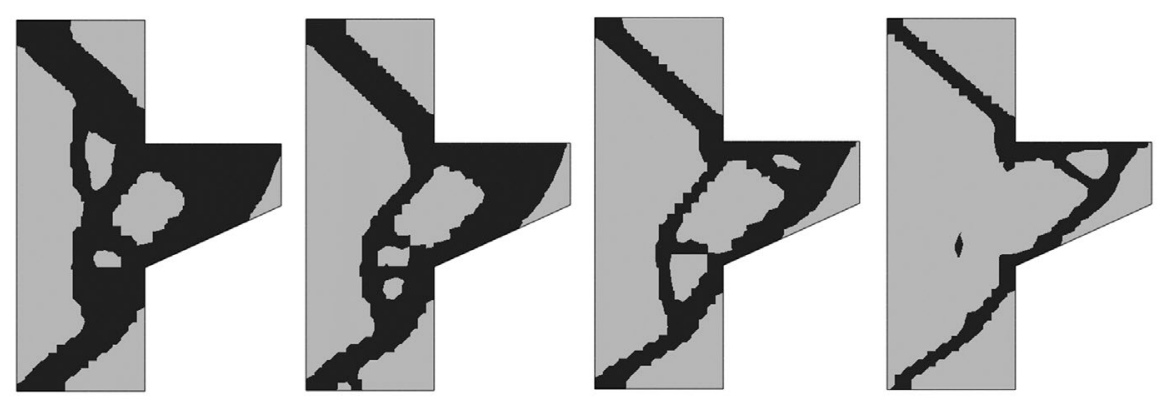

Figure 14. Optimized distribution of material for mesh a), volume fractions of $50 \%, 40 \%, 30 \%$ and $20 \%$, respectively.

For mesh (b), the obtained optimized topologies when considering volume fractions of approximately $50 \%, 40 \%$, $30 \%$, and $20 \%$ of the initial volume are presented in Figure 15 . To reach the desired parameters, 37, 36, 37, and 49 cycles of project were necessary, respectively. A better visualization of material distribution in this mesh was conducted, assisting in the process of conception of strut and tie model.
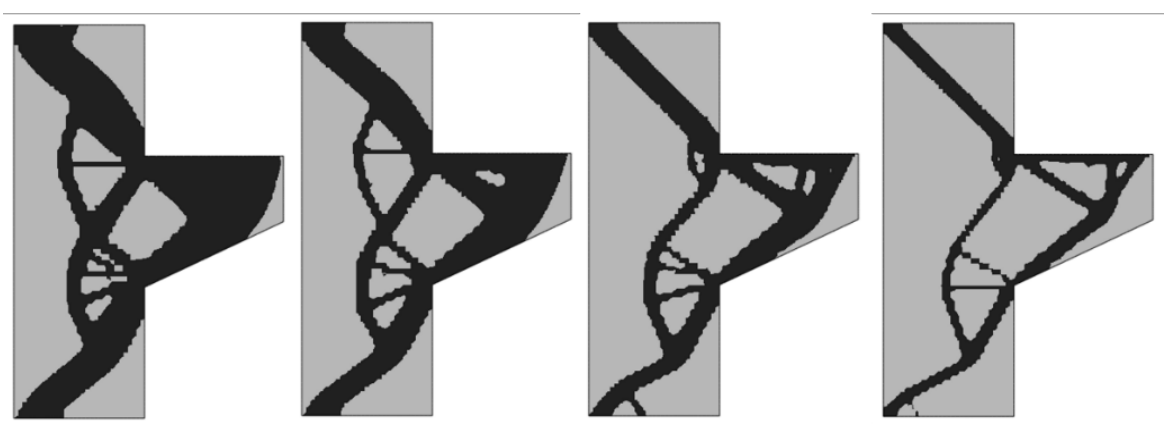

Figure 15. Optimized distribution of material for mesh b), volume fractions of $50 \%, 40 \%, 30 \%$ and $20 \%$, respectively.

In Figures 16 and 17 the principal stress trajectories for mesh (b) are presented, with the optimized models $\mathrm{f}=50 \%$ and $\mathrm{f}=40 \%$, respectively. The principal stresses of tension (a) are indicated in blue, and, in red, principal stresses of compression (b). With the identified regions, a truss model for the analysis of internal loads may be defined. 

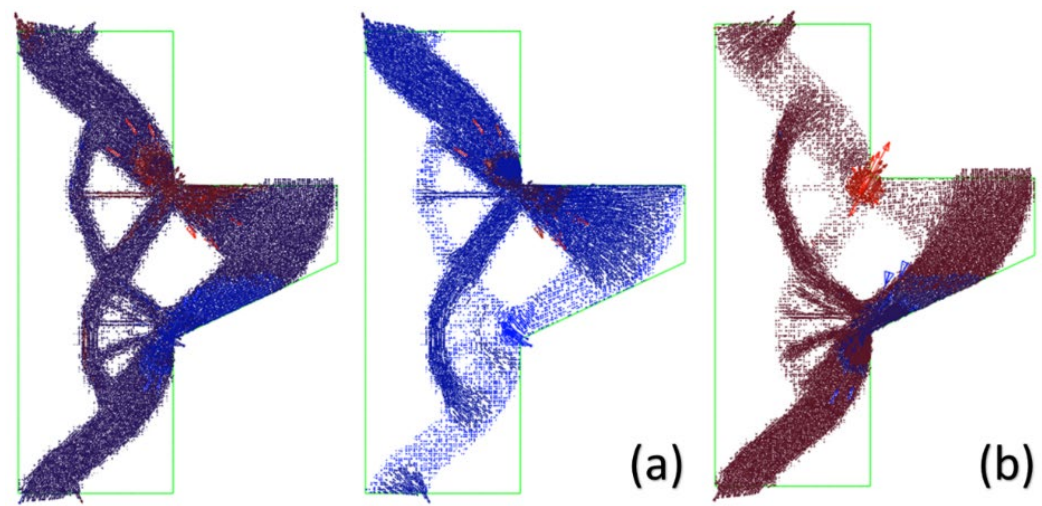

Figure 16. Principal stress trajectories for $\mathrm{f}=50 \%$ (a: tension; $\mathrm{b}$ : compression)
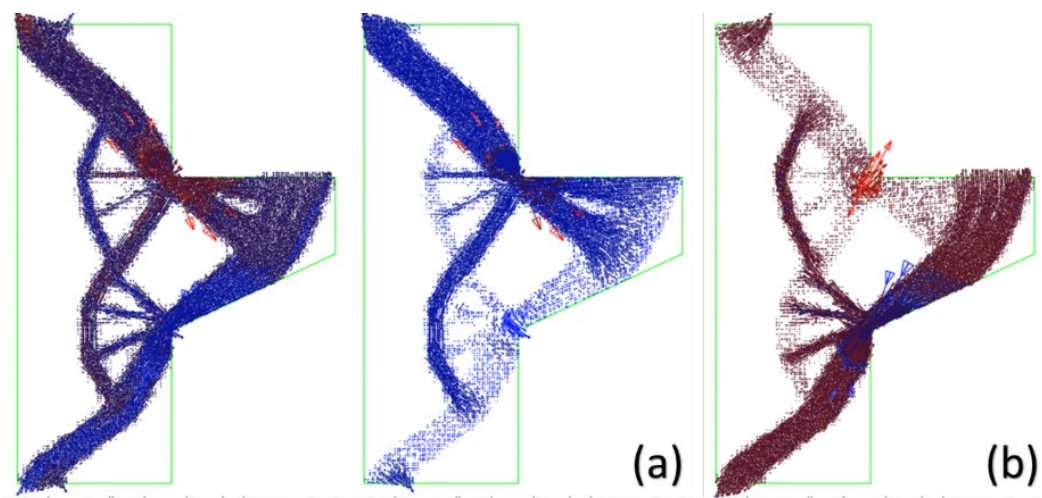

Figure 17. Principal stress trajectories for $\mathrm{f}=40 \%$ ( $\mathrm{a}$ : tension; $\mathrm{b}$ : compression)

Based on the optimized topologies obtained for mesh (b), in the different volume fractions $\mathrm{f}=50 \%$ (Figure 18a) and $f=40 \%$ (Figure 18b), the connectivity of the resultant elements of the optimized models are presented, offering the indicative of truss models. The nodes coordinates are presented in Tables 6 and 7.
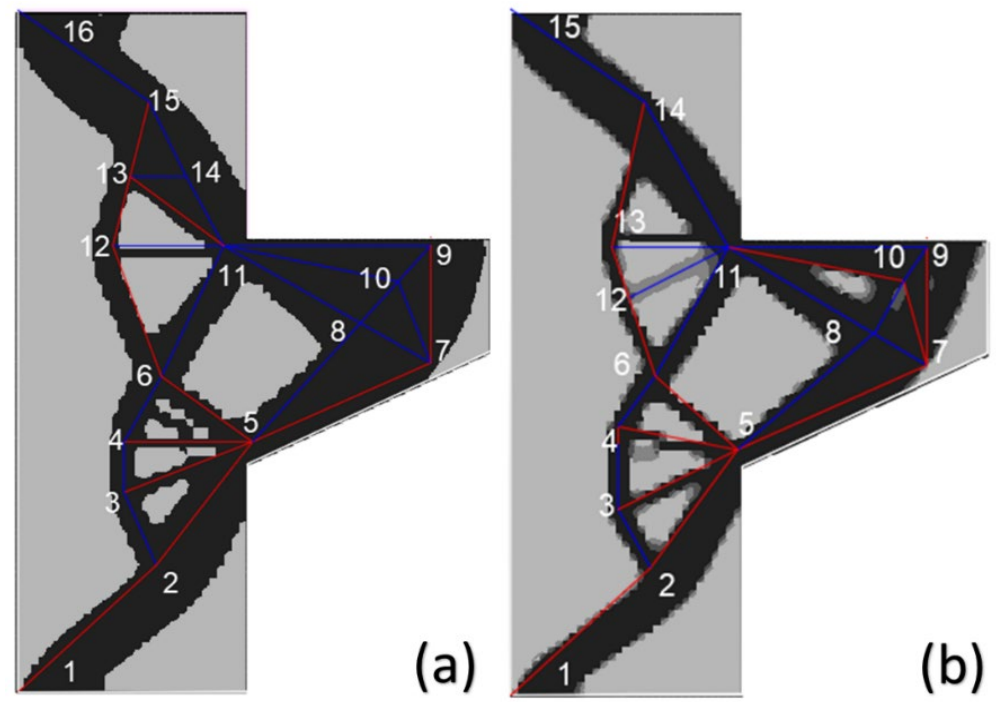

Figure 18. Suggested truss models for the trapezoidal corbel a) $f=50 \%$; $b$ ) $f=40 \%$ 
Table 6. Coordinates of truss model for $\mathrm{f}=50 \%$

\begin{tabular}{|c|c|c|}
\hline Node & x (cm) & $y(\mathrm{~cm})$ \\
\hline 1 & 0.00 & 0.00 \\
\hline 2 & 48.3 & 44.74 \\
\hline 3 & 36.97 & 70.00 \\
\hline 4 & 36.97 & 88.00 \\
\hline 5 & 81.65 & 88.00 \\
\hline 6 & 49.91 & 111.00 \\
\hline 7 & 144.00 & 115.64 \\
\hline 8 & 118.00 & 129.86 \\
\hline 9 & 144.00 & 157.00 \\
\hline 10 & 132.68 & 144.43 \\
\hline 11 & 71.77 & 157.00 \\
\hline 12 & 32.97 & 157.00 \\
\hline 13 & 39.14 & 181.43 \\
\hline 14 & 58.88 & 181.43 \\
\hline 15 & 45.84 & 207.77 \\
\hline 16 & 0.00 & 240.00 \\
\hline
\end{tabular}

Table 7. Coordinates of truss model for $\mathrm{f}=40 \%$

\begin{tabular}{ccc}
\hline Node & $\mathbf{x}(\mathbf{c m})$ & y (cm) \\
\hline 1 & 0.00 & 0.00 \\
\hline 2 & 48.30 & 44.74 \\
\hline 3 & 36.97 & 65.00 \\
\hline 4 & 36.97 & 94.00 \\
\hline 5 & 78.00 & 86.00 \\
\hline 6 & 49.91 & 111.50 \\
\hline 7 & 144.00 & 115.64 \\
\hline 8 & 126.34 & 127.00 \\
\hline 10 & 144.00 & 157.00 \\
\hline 11 & 135.90 & 145.07 \\
\hline 12 & 75.00 & 157.00 \\
\hline 13 & 40.64 & 138.50 \\
\hline 14 & 34.50 & 157.00
\end{tabular}

For the problem in the analysis, the strut strength according to each normative code is presented in Table 8 . It is emphasized that the same criteria mentioned in the previous example was adopted for the calculated values.

Table 8. Strut strength

\begin{tabular}{cc}
\hline Model & Strength $\left(\mathbf{k N} / \mathbf{m}^{\mathbf{2}}\right)$ \\
\hline NBR 9062 [1] & $9,462.38$ \\
\hline ACI 318 [10] & $10,200.00$ \\
\hline Eurocode 2 [11] & $10,426.66$ \\
\hline
\end{tabular}

Figure 19 presents the internal loads for the two analyzed models. The positive loads (in blue) indicate tension, while the negative loads (in red) indicate compression. The detail of the loads in the bars for models $\mathrm{f}=50 \%$ (a) and $\mathrm{f}=40 \%$ (b) in the corbel region is shown, and the steel reinforcement area was found for the main tie, according to Table 9. 

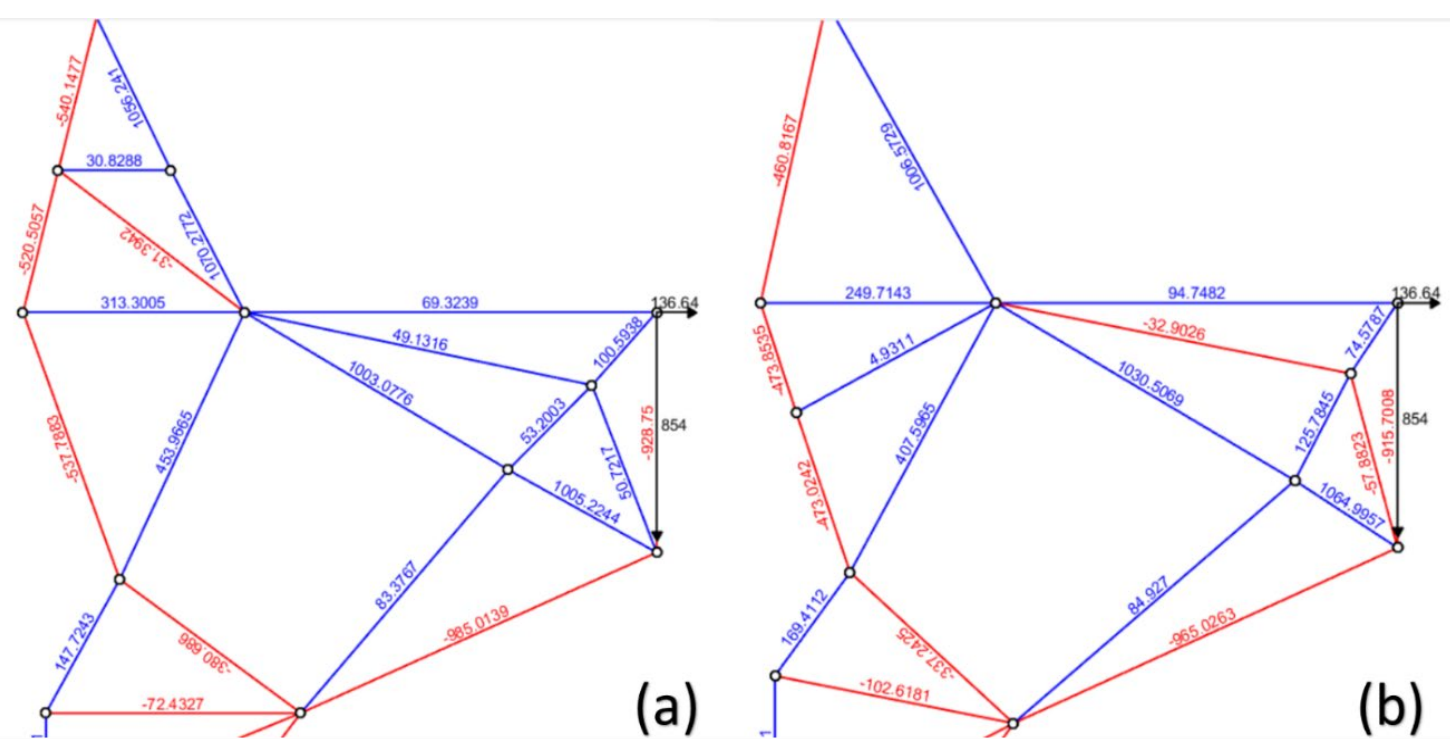

Figure 19. Load details in the trapezoidal corbel a) $\mathrm{f}=50 \%$; b) $\mathrm{f}=40 \%$

Table 9. Reinforcement areas of the main tie

\begin{tabular}{cc}
\hline Model & Steel $\mathbf{a r e a ~}_{\left(\mathbf{c m}^{2}\right)}$ \\
\hline NBR 9062 [1] & 21.43 \\
\hline PCI (2010) [19] & 26.38 \\
\hline Eurocode 2 [1] & 22.19 \\
\hline
\end{tabular}

Similar to the example of the rectangular corbel, the main tie was designed according to the load located in an inclined bar, suggesting that the main reinforcement should also be inclined. This was not indicated for the building routine, due to the great probability of occurring a displacement of the reinforcement during the execution.

For the horizontal ties, in the models with $\mathrm{f}=50 \%$ and $\mathrm{f}=40 \%$ (bars $9-11$ ), the steel reinforcement areas were $1.59 \mathrm{~cm}^{2}$ and $2.18 \mathrm{~cm}^{2}$, respectively. When analyzing the inclined ties (bars $11-14$ and $7-8$, in this order, for $\mathrm{f}=50 \%$ and $\mathrm{f}=40 \%$ ), mentioned before, the steel reinforcement areas were $24.61 \mathrm{~cm}^{2}$ and $24.50 \mathrm{~cm}^{2}$, respectively.

Considering the indication of Araújo [20], for the two-strut models, the computation of the width of the strut depends on the bearing pad dimensions. For the vertical struts, in case in analysis, the width $\mathrm{c}_{2}$ was determined equal to $38 \mathrm{~cm}$ for the models with optimized topologies the same as the width of the bearing pad.

In the model with $\mathrm{f}=50 \%$, the stress in the strut was $3,055.09 \mathrm{kN} / \mathrm{m}^{2}$, and for the model with $\mathrm{f}=40 \%$, the stress in the strut was $3,012.17 \mathrm{kN} / \mathrm{m}^{2}$. Despite the most loaded struts (bars 5-7) being located in the lower region of the corbel, it is highlighted that obtaining these widths was a difficult process.

For the models with optimized topologies, comparing with the lower strength, in this case, the one in NBR 6118 [3], they presented no concrete crushing, which indicates that the stress levels were safe.

In this new example, the steel reinforcement areas of the inclined ties obtained through the models with optimized topologies were coherent with the design codes. Since each model has its particularity in the methodology of analysis, it can be asserted that the developed models through the connectivity of the materials may be used as an assistance for design.

\section{CONCLUSIONS}

The fundamentals of the strut and tie model are directly related to the topology optimization problem of continuum structures. To maximize the stiffness and search for an optimized model, based on the criterion of minimum strain energy, the optimized topologies serve as assistance in the definition of representative truss models of the elements with geometrical and static discontinuities.

Even with a vast development in technical specifications, the research in the area of topology optimization, in general, does not emphasize the design of structural elements in discontinuity regions, focusing on just discussing the 
computational aspects. The task to interpret the result through the material distribution, as a strength mechanism through the truss bars, is still a challenge, because many parameters are involved in the process.

As a representation of preliminary truss models, the constraint in the optimization problem in which the volume fraction is about $40 \%$ to $50 \%$ was shown adequately as an indicative of initial analysis. Elevated fractions (above $50 \%$ ) do not suppress the necessary amount of material for the visualization of the load path in the optimized model. Related to the mesh refinement, which depends on each analyzed geometry, in the presented cases, the results were satisfactory for the analysis in plane stress state with quadrilateral finite elements of edges of an approximate size of $25 \mathrm{~mm}$.

The obtained results through topology optimization may be considered, in every case, as preliminary truss models. It should be considered that the proceeding is not conceived for the complete design. In general, the results should be validated by verified formulations in experimental analyses. To check the ductility criterion, it is necessary to verify if additional reinforcement will be necessary, in such a way as to assure that the model is agreeing with the lower bound theorem of the theory of plasticity.

For the development of optimized models, various aspects related to the project should be checked, such as the restraint factors of execution, financial availability, and specialized labor. A profound study and a larger structural sensibility, using the optimization tools will enable the engineer to develop bolder and cheaper projects.

\section{ACKNOWLEDGEMENTS}

The authors acknowledge the National Council for Research and Development (CNPq) for the financial support provided in this research and the Laboratory of Scientific Computing and Visualization (LCCV), from Technology Center (CTEC) at Federal University of Alagoas (UFAL).

\section{REFERENCES}

[1] Associação Brasileira de Normas Técnicas, Projeto e Execução de Estruturas de Concreto Pré-Moldado, NBR $9062,2017$.

[2] M. K. El Debs, Concreto Pré-Moldado: Fundamentos e Aplicações, 2. ed. São Paulo: Oficina de Textos, 2017.

[3] Associação Brasileira de Normas Técnicas, Projeto de Estruturas de Concreto: Procedimento, NBR 6118, 2014.

[4] Q. Q. Liang, Y. Xie, and G. P. Steven, "Topology optimization of strut-and-tie models in reinforced concrete structures using an evolutionary procedure," ACI Struct. J., vol. 97, no. 2, pp. 322-330, 2000.

[5] J. C. Pantoja, "Geração automática via otimização topológica e avaliação de segurança de modelos de bielas e tirantes," Ph.D. dissertation, Pont. Univ. Cat. Rio de Janeiro, Rio de Janeiro, 2012.

[6] Q. Q. Liang, Performance-Based Optimization of Structures: Theory and Applications. London: Spon Press, 2004.

[7] V. S. Almeida, H. L. Simonetti, and L. Oliveira No., "Análise de modelos de bielas e tirantes para estruturas de concreto armado via uma técnica numérica," Rev. IBRACON Estrut. Mater., vol. 6, no. 1, pp. 139-157, 2013.

[8] M. B. B. F. Guerra, "Modelos de concepção para estruturas em concreto armado com comportamento não linear obtidos pelo método de bielas e tirantes e otimização topológica,” Ph.D. dissertation, Univ. Fed. Minas Gerais, Belo Horizonte, 2017.

[9] M. B. B. F. Guerra and M. Greco, "Modelos de concepção para estruturas de concreto armado com comportamento não linear obtidos pelo método de bielas e tirantes e otimização topológica," Rev. Sul-Americana Eng. Estrut., vol. 14, no. 1, pp. 59-78, 2017.

[10] American Concrete Institute, Building Code Requirements for Structural Concrete, ACI 318-14, 2014.[11] European Committee for Standardization, Eurocode 2: Design of Concrete Structures: General Rules and Rules for Buildings, EN 1992-1-1, 2004.

[12] S. El-Metwally and W. F. Chen, Structural Concrete: Strut-and-Tie Models for Unified Design. Boca Raton: CRC Press, 2018.

[13] C. Williams, D. Deschenes, and O. Bayrak, Strut-and-Tie Model Design Examples for Bridges: Final Report. Texas: Texas Dep. Transportation, 2012.

[14] J. Schlaich, K. Schäfer, and M. Jennewein, "Toward a consistent design of structural concrete," PCI J., vol. 32, no. 3, pp. 74-150, 1987.

[15] R. A. Souza, "Concreto estrutural: análise e dimensionamento de elementos com descontinuidades,” Ph.D. dissertation, Esc. Politécnica, Univ. São Paulo, São Paulo, 2004.

[16] O. Sigmund, "A 99 line topology optimization code written in MatLab," Struct. Multidiscipl. Optim., vol. 21, no. 2, pp. 120-127, 2001.

[17] M. P. Bendsøe and N. Kikuchi, "Generating optimal topologies in structural design using a homogenization method," Comput. Methods Appl. Mech. Eng., vol. 71, no. 2, pp. 197-224, 1998.

[18] Simulia, ABAQUS® User's Manual vol. 2, 2014.

[19] Precast/Prestressed Concrete. PCI Design Handbook: Precast and prestressed concrete. 7 ed. Chicago, 2010. 
[20] J. M. Araújo, Curso de Concreto Armado: vol. 4, 3. ed. Rio Grande: Dunas, 2010.

[21] R. C. Silva, “Concreto armado: aplicações de modelos de bielas e tirantes,” M.S. thesis, Esc. Eng. São Carlos, Univ. São Paulo, São Carlos, 1991.

Author contributions: M.B.M., Cedrim: conceptualization, methodology, analysis, writing; E.N., Lages and A.S.R., Barboza: conceptualization, methodology, analysis, writing, supervision.

Editors: Fernando Fonseca, José Luiz Antunes de Oliveira e Sousa, Guilherme Aris Parsekian. 